\title{
Results of a program for the prevention of blindness caused by retinopathy of prematurity in southern Brazil
}

\author{
João Borges Fortes Filho, ${ }^{1}$ Cristiano Koch Barros, ${ }^{2}$ Marlene Coelho da Costa, ${ }^{3}$ \\ Renato S. Procianoy 4
}

\begin{abstract}
Objective: To describe the results of a program for the prevention of blindness caused by retinopathy of prematurity implemented in 2002 at a tertiary-care hospital, according to screening criteria adopted in Brazil, and to compare some aspects with the criteria adopted by other countries.
\end{abstract}

Methods: Descriptive observational study including all preterm infants born at this hospital weighing $\leq 1,500 \mathrm{~g}$ at birth and/or gestational age $\leq 32$ weeks who survived up to the sixth week after birth, between October 2002 and June 2006. Ophthalmic examinations were performed from the sixth week of life and repeated as necessary until remission of the disease.

Results: A total of 300 newborns were included and there were 18 cases of treatable threshold disease (18/300, $6 \%$ ) according to the Brazilian criteria. One patient was not treated because $\mathrm{s} /$ he developed the disease after hospital discharge and did not turn up for examination in order to initiate treatment. According to the criteria suggested by industrialized countries, the total number of exams would be reduced under the same circumstances, but $11.76 \%$ of the cases of threshold disease would not be detected.

Conclusions: The Brazilian criteria for neonatal screening were efficient in detecting treatable cases. Blindness was averted in 17 preterm infants in the study period. The universal use of such program at teaching hospitals or in the public and private health networks could help prevent one of the main causes of preventable and treatable blindness among infants in developing countries. Currently, a change in these criteria in Brazil may compromise the diagnosis of some treatable patients.

J Pediatr (Rio J). 2007;83(3):209-216: Prematurity, retinopathy of prematurity, retinopathy of prematurity/ epidemiology/incidence/prevention \& control, blindness/prevention \& control, screening.

\section{Introduction}

Retinopathy of prematurity (ROP) is one of the major causes of blindness among infants. It is characterized by an epidemic pattern in several Latin American countries, including Brazil. ${ }^{1,2}$ The incidence of blindness caused by ROP varies across countries, and is influenced by the quality of perinatal care and by the existence or not of screening programs for the early diagnosis of the disease. ${ }^{3}$

This has been confirmed by reports of higher survival rates among very low birth weight and extremely low birth

1. Mestre. Doutorando em Oftalmologia, Universidade Federal de São Paulo (UNIFESP), São Paulo, SP, Brasil. Professor, Universidade Federal do Rio Grande do Sul (UFRGS), Porto Alegre, RS, Brasil. Chefe, Setor de Retinopatia da Prematuridade, Hospital de Clínicas de Porto Alegre (HCPA), Porto Alegre, RS, Brasil.

2. Acadêmico de Medicina, UFRGS, Porto Alegre, RS, Brasil. Pesquisador, Setor de Retinopatia da Prematuridade, HCPA, Porto Alegre, RS, Brasil.

3. Enfermeira, Centro de Neonatologia, HCPA, Porto Alegre, RS, Brasil.

4. Professor titular, UFRGS, Porto Alegre, RS, Brasil. Chefe, Serviço de Neonatologia, HCPA, Porto Alegre, RS, Brasil.

Manuscript received Oct 03 2006, accepted for publication Dec 192006.

Suggested citation: Fortes Filho JB, Barros CK, da Costa MC, Procianoy RS. Results of a program for the prevention of blindness caused by retinopathy of prematurity in southern Brazil. J Pediatr (Rio J). 2007;83(3):209-216.

doi 10.2223/JPED.1611 
weight preterm infants, higher pregnancy rates among adolescents from a lower social background without proper prenatal care in order to reduce the risks of preterm birth, larger incidence of multiple pregnancies due to fertility treatments, existence of more neonatal units and lack of ophthalmic care in most neonatal units of these countries. ${ }^{4}$

Neonatal screening programs were implemented after the 1990s, when preliminary studies of the Multicenter Trial of Cryotherapy for Retinopathy of Prematurity yielded thriving results for the treatment of ROP. ${ }^{5}$

Numerous screening criteria were established in different countries, but it is difficult to determine which are ideal, owing to the specific characteristics of each region. The ideal model should contemplate examinations of all preterm infants at risk for severe forms of the disease. ${ }^{3}$

The Brazilian guidelines for neonatal screening were established in 2002, in the 1st Workshop on Retinopathy of Prematurity (1st WK), organized by the International Agency for the Prevention of Blindness, Vidi Institute, Brazilian Council for Ophthalmology and by the Brazilian Society of Pediatrics. After analyzing the situation of ROP in Brazil, it was found out that preterm infants were not screened for ROP in most cities, thus raising the prevalence of blindness or severe visual impairment. ${ }^{6}$ In this workshop, it was difficult to determine the number of infants visually impaired by ROP in Brazil, since there were no guidelines for the diagnosis or treatment on a national basis, with just some initiatives in some public or private hospitals, which employed different criteria for diagnosis and treatment.

Then, the neonatal screening of preterm infants with birth weight $(\mathrm{BW}) \leq 1,500 \mathrm{~g}$ and/or gestational age (GA) $\leq 32$ weeks was implemented, which included indirect binocular ophthalmoscopy (IBO) and pupil dilation between the fourth and sixth weeks of life at the Neonatal Intensive Care Unit (NICU). The assessments were repeated, according to the classification of ROP observed or based on risk factors (RF) for each patient. $^{7}$

Using these criteria, a program for the prevention of blindness due to ROP was implemented in 2002, with systematic weekly examination of preterm infants at risk, scheduled for neonatal screening from their birth, in addition to an outpatient follow-up program for surviving infants up to their first year of life.

The aim of this study is to present the results of this program by comparing Brazilian criteria with those used in other countries.

\section{Methods}

The study protocol was approved by the Research Ethics Committee, and included all preterm infants born at that hospital with $\mathrm{BW} \leq 1,500 \mathrm{~g}$ or with $\mathrm{GA} \leq 32$ weeks who survived up to the sixth week of life, when the initial ophthalmic examination was performed, between October 2002 and June 2006. Only those preterm infants who died before initial ophthalmic examination were excluded from the study.

The clinical outcome corresponded to the onset of ROP at any stage of development. The stages always corresponded to the worst level of retinopathy found in any of the eyes during patient follow-up. All patients were initially examined at the NICU and followed up at the outpatient clinic until vascularization of the temporal retina was completed or up to the full stabilization of retinopathy after treatment.

There are no data about those preterm infants who died after initial examination, after being discharged from the NICU or about those who did not turn up for follow-up visits.

Ophthalmic examination consisted of examination of the ocular fundus using pupil dilation (with the combined use of $0.5 \%$ tropicamide and $2.5 \%$ phenylephrine eyedrops), under IBO with a 28 diopter lens (Nikon ${ }^{\circledR}$, Melville, NY, USA) and eye lid speculum (Alfonso Eye Speculum, Storz ${ }^{\circledR}$, Bausch \& Lomb Inc., San Dimas, CA, USA). Scleral indentation was used whenever necessary.

The overall incidence and the incidence by the staging of retinopathy according to the international classification of 1984/1987 were determined. ${ }^{8,9}$

Patients with ROP 2 or 3 were submitted to weekly examination in order to guarantee that no case of threshold disease could go unnoticed and left untreated (threshold disease: classically defined as the ideal time for treatment, after which the risk of an unfavorable functional outcome or of progression to blindness occurs in $50 \%$ of patients). ${ }^{7}$

The RF to define the periodicity of assessments were extreme prematurity, septicemia, use of transfusions or erythropoietin, low weight gain after birth and oxygen therapy through mechanical ventilation or continuous positive airway pressure (CPAP).

These criteria were compared with more selective ones, used in industrialized countries (USA 1997/2001 and United Kingdom 1996/2005), to determine whether the same number of patients with threshold disease could be detected.

For treatment, an FTC $2500{ }^{\circledR} 810 \mathrm{~nm}$ laser diode (Opto, São Carlos, SP, Brazil) was used in a transpupillary way under IBO, general anesthesia or sedation. Both eyes were treated on the same occasion, after identification of threshold disease.

Statistical analyses were carried out using SPSS (SPSS ${ }^{\circledR}$ 13.0 for Windows ${ }^{\circledR}$, SPSS Inc., Chicago, IL, USA). 


\section{Results}

The sample included 300 preterm newborn infants (PNI). Seventy-four patients (24.67\%) had ROP. Threshold disease affected 18 patients $(6 \%)$. The staging of retinopathy with its respective incidence rates can be seen in Table 1.

Table 1 - Incidence of retinopathy of prematurity in 300 preterm infants with birth weight $\leq 1,500$ g or gestational age $\leq 32$ weeks between 2002 and 2006

\begin{tabular}{ccc}
\hline & No. of PNI assessed & (\%) ROP \\
\hline Without ROP & 226 & $75.33 \%$ \\
With ROP & 74 & $24.67 \%$ \\
ROP 1 & 33 & $11.00 \%$ \\
ROP 2 & 23 & $7.67 \%$ \\
ROP 3 & 16 & $5.33 \%$ \\
ROP 4 & 1 & $0.33 \%$ \\
ROP 5 & 1 & $0.33 \%$ \\
Total & 300 & $100 \%$ \\
& & \\
\hline
\end{tabular}

$\mathrm{PNI}=$ preterm newborn infant $; \mathrm{ROP}=$ retinopathy of prematurity.

Blindness was averted in 17 preterm infants after laser treatment when threshold disease occurred. One patient developed threshold disease after initial examination and did not return for follow-up visits after discharge. This patient reached stage 5 of ROP and total bilateral blindness. Table 2 shows the characteristics and results of treatment in patients with threshold disease.

The patients who developed threshold disease were compared with the criteria adopted in the USA (1997/2001) and in the United Kingdom (1996/2005). The comparison revealed that threshold disease had not been diagnosed in two patients, corresponding to $11.76 \%$ (Tables 3 and 4 ).

\section{Discussion}

Prevention of blindness in neonatal units is a recent concept. If screening programs for retinopathy were carried out, the number of visually impaired individuals of a community could be remarkably reduced. ${ }^{10}$

ROP has been the major cause of blindness among infants in industrialized and developing countries, due to the high survival rate of preterm infants with lower BW and lower GA. ${ }^{2}$ The World Health Organization (WHO) estimated that of 100,000 visually impaired infants in Latin America in 2005, 24,000 cases resulted from ROP. ${ }^{1}$

This occurred due to the improvement in perinatal care resulting from the larger number of hospitals specialized in the treatment of risky pregnancies and from the increase in the survival of extremely preterm infants from 8 to $35 \%$, approximately, in some centers, with a disease incidence around $47 \%$ for those infants weighing between 1,000 and $1,250 \mathrm{~g}$ at birth. ${ }^{11,12}$ In other centers, the chance of survival of infants with GA of 27 to 28 weeks amounted to $90 \%$ and to $95 \%$ in those with more than 32 weeks; however, these figures vary considerably from one country to another. ${ }^{13}$

Among the improvements in prenatal care, we can cite the preventive use of corticosteroids and prenatal assistance in preventing preterm births. The improvement in perinatal care after a preterm birth included the use of incubators with controlled heat source, high-quality mechanical respirators, high-frequency respirators, devices such as CPAP for immediate use after birth, availability of surfactant, erythropoietin, indomethacin, in addition to ultrasound and $\mathrm{x}$-ray equipment for the detection of comorbidities associated with prematurity. ${ }^{14}$

Since 1966, WHO has used "years of blindness" as a way to measure the extent of blindness across countries. This factor is obtained by multiplying the number of affected individuals by the number of estimated survival years. Thus, it is possible to compare the prevalence rates of different diseases and their impact on public health. ${ }^{15}$ In Brazil, childhood blindness has shown great socioeconomic importance when assessed by this factor, since those infants who are born blind or visually impaired at a very early age will live to the age of 70, approximately, on social security without ever having contributed to it. Moreover, blindness also affects children's cognitive, psychomotor and social development throughout their lifetime.

Data from the Ministry of Health, obtained from the 1 st WK, show that 15,000 preterm infants were at risk for ROP in 2001 . Given that $7.5 \%$ of them developed threshold disease and that $50 \%$ would be blind if left untreated, the approximate number of blind infants/year in Brazil amounted to 562 , with a high socioeconomic cost, since ROP is a disease that causes severe, but treatable, visual impairment. The number of affected infants is expected to double within the next 20 years if preventive measures are not taken.

Ophthalmological studies have shown that neonatal screening programs are virtually nonexistent in most Brazilian cities, except in major capital cities and at teaching hospitals. $^{7,16}$ Therefore, nationwide neonatal screening programs are of paramount importance. ${ }^{12,16}$ 
The program implemented at our institution also included the introduction of knowledge on ROP in medical schools, in residency programs in ophthalmology and neonatology and for the nursing staff. In order to improve the program, aiming at the efficient control of RF for the development of retinopathy, ophthalmologists and neonatologists interacted closely. Therefore, we have managed to qualify ophthalmologists and technical staff for working with preterm infants at risk for ROP, one of the aims of the 1st WK. Another highlight of the program was the creation of a research line involving the Departments of Ophthalmology,
Neonatology, Genetics and Nursing, with the participation of undergraduate students, residents, graduate students and professors.

The results of this study showed that by using the Brazilian criteria, we could detect 18 cases of threshold disease, with probable progression to blindness if untreated. The $6 \%$ incidence of treatable ROP (18/300) is an important indicator of the quality of perinatal care at the hospital, which can be compared to the data from other hospitals, either in Brazil or in other countries that are far more developed than Brazil. ${ }^{17,18}$

Table 2 - Characteristics and results in 18 patients with threshold disease between 2002 and 2006

\begin{tabular}{|c|c|c|c|c|c|c|c|c|}
\hline Case & BW & GA & Sex & ROP & Zone & GA at treatment & No. of treatments & Outcome \\
\hline 1 & 620 & 25 & $\mathrm{~F}$ & ROP $3+$ & II & 36 & 1 & Remission \\
\hline 2 & 625 & 26 & $\mathrm{~F}$ & ROP $3+$ & II & 36 & 2 & Remission \\
\hline 3 & 635 & 27 & $\mathrm{~F}$ & ROP $3+$ & II & 36 & 1 & Remission \\
\hline 4 & 700 & 26 & $\mathrm{~F}$ & ROP $3+$ & II & 36 & 1 & Remission \\
\hline 5 & 710 & 26 & $\mathrm{~F}$ & ROP $3+$ & II & 36 & 1 & Remission \\
\hline 6 & 755 & 25 & $\mathrm{~F}$ & ROP $3+$ & II & 36 & 1 & Remission \\
\hline 7 & 780 & 31 & M & ROP $3+$ & II & 40 & 2 & Remission \\
\hline 8 & 870 & 30 & $M$ & ROP $3+$ & II & 40 & 1 & Remission \\
\hline 9 & 900 & 31 & $M$ & ROP $3+$ & II & 40 & 1 & Remission \\
\hline 10 & 920 & 30 & M & ROP $3+$ & II & 38 & 2 & ROP 4B AO \\
\hline 11 & 935 & 30 & M & ROP $3+$ & II & 37 & 1 & Remission \\
\hline 12 & 990 & 29 & $M$ & ROP $3+$ & II & 39 & 1 & Remission \\
\hline 13 & 1,080 & 26 & $\mathrm{~F}$ & ROP $3+$ & II & 37 & 1 & Remission \\
\hline 14 & 1,230 & 31 & M & ROP $3+$ & II & 40 & 1 & Remission \\
\hline 15 & 1,260 & 28 & M & ROP $3+$ & II & 37 & 1 & Remission \\
\hline 16 & 1,315 & 32 & $M$ & ROP $3+$ & II & 41 & 1 & Remission \\
\hline 17 & 1,500 & 30 & $\mathrm{~F}$ & ROP $3+$ & II & 40 & 1 & Remission \\
\hline 18 & 710 & 29 & $\mathrm{~F}$ & ROP $2+$ & II & Not treated & 0 & ROP 5 AO \\
\hline Mean & 918.61 & 20.44 & & & Mean & 37.94 & & \\
\hline Median & 885 & 29 & & & Median & 37 & & \\
\hline SD & 263.40 & 2.33 & & & SD & 1.89 & & \\
\hline Min & 620 & 25 & & & Min & 36 & & \\
\hline Max & 1,500 & 32 & & & $\operatorname{Max}$ & 41 & & \\
\hline
\end{tabular}

$\mathrm{BW}=$ birth weight $; \mathrm{GA}=$ gestational age; Max = maximum; Min = minimum; ROP = retinopathy of prematurity $; \mathrm{SD}=\mathrm{standard}$ deviation . 
Based on the results of 16 programs for the diagnosis and treatment of ROP, presented in the 1 st WK, it was shown that ROP 3, threshold disease, affected nearly $7.5 \%$ of preterm infants with mean BW and GA of $948 \mathrm{~g}$ and 28.5 weeks, respectively. ${ }^{17}$

Table 2 shows that the mean BW and GA in the group of patients who developed threshold disease in this hospital corresponded to $918.61 \mathrm{~g}$ (median $885 \mathrm{~g}$; SD 263.39) and 28.44 weeks (median 29 weeks; SD 2.33). The patients with threshold disease were treated at around 38 weeks of life (median 37; SD 1.89). These data are also comparable to the results obtained in other centers. ${ }^{18,19}$

The survival rate among very low birth weight preterm infants (BW $\leq 1,500 \mathrm{~g}$ or GA $\leq 32$ weeks) was around $70.11 \%$ and $33.67 \%$ among extremely low birth weight preterm infants (BW $\leq 1,000 \mathrm{~g}$ or $\mathrm{GA} \leq 28$ weeks) in this hospital during the study period.

Recently, there has been a tendency towards revising the screening criteria initially established in several countries, in order to make the programs economically feasible by reducing the number of unnecessary examinations and by maintaining the same efficacy in the detection of the disease. ${ }^{20}$ Table 3 shows the screening criteria commonly used in several countries.

In the USA, the American Academy of Pediatrics (AAP), the American Academy of Ophthalmology (AAO) and the American Association for Pediatric Ophthalmology and Strabismus (AAPOS) ${ }^{21}$ have restricted the treatment of infants with $\mathrm{BW} \leq 1,500 \mathrm{~g}$ or $\mathrm{GA} \leq 28$ weeks or in the case of severe clinical intercurrent events at the discretion of the neonatologist, since 1997. In England, the Royal College of Ophthalmologists and the British Association of Perinatal Medicine 22 have recommended the treatment of preterm infants with $\mathrm{BW} \leq 1,500 \mathrm{~g}$ or $\mathrm{GA} \leq 31$ weeks since 1996 .

Had these criteria been applied to our sample, we would have detected all 18 cases of threshold disease. This would have been possible since there was no case of threshold disease among infants with $\mathrm{BW}>1,500 \mathrm{~g}$ or with GA $>32$ weeks in our study population.

Table 3 - Screening criteria for retinopathy of prematurity in several countries and in Brazil

\begin{tabular}{lcccc}
\hline Country & Year & BW criteria & GA criteria & Clinical criteria \\
\hline USA & 1997 & & 28 & RF* \\
USA & 2001 & 1,500 & 28 & RF* \\
USA & 2006 & 1,250 & 32 & RF* \\
Canada & 2000 & 1,500 & 30 & - \\
United Kingdom & 1996 & 1,500 & 31 & $\mathrm{O}^{2}+24 \mathrm{~h}$ \\
United Kingdom & 2005 & 1,500 & 30 & - \\
Spain & $1991-1998$ & 1,250 & 33 & - \\
Spain & 2001 & 1,500 & 30 & - \\
Sweden & 1993 & 1,250 & 32 & - \\
Sweden & 2002 & - & 31 & - \\
Denmark & 1990 & - & 32 & - \\
Denmark & 2004 & 1,750 & 31 & - \\
India & 2006 & 1,500 & 32 & RF* \\
Brazil & 2002 & 1,750 & 32 & \\
& & 1,500 & &
\end{tabular}

* RF: Any preterm infant with risk factors for retinopathy of prematurity. When requested by the attending neonatologist. USA 2006: BW >1,500 g < 2,000 g or GA > 32 weeks with unstable clinical course.

$\mathrm{BW}=$ birth weight; $\mathrm{GA}=$ gestational age; $\mathrm{RF}=$ risk factor. 
U.S. centers in 2001 and English centers in 2005 reassessed the criteria, showing a tendency towards reducing the coverage of their programs, recommending the examination of infants with BW less than $1,250 \mathrm{~g}$ or with $\mathrm{GA}<30$ weeks (United Kingdom) and $<28$ weeks (USA). ${ }^{23,24}$

If we applied these new criteria to this study, two cases of threshold disease would not be detected (corresponding to $11.76 \%$ of those detected by the Brazilian criteria). The number of preterm infants included in the screening program would be reduced to 202 .

In 2006, U.S. centers, after publication of the final results of the Multicenter Trial of Cryotherapy for Retinopathy of Prematurity and of the Early Treatment for Retinopathy of Prematurity Randomized Trial Study, 25,26 established new guidelines for neonatal screening. All infants with $\mathrm{BW} \leq 1,500 \mathrm{~g}$ or $\mathrm{GA} \leq 32$ weeks or selected cases of infants with BW between 1,500 and $2,000 \mathrm{~g}$ or $\mathrm{GA}>32$ weeks that had important clinical intercurrent events must be examined, thus broadening the coverage of the screening programs. Treatment may be indicated in case of pre-threshold disease (defined by The International Classification of Retinopathy of Prematurity Revisited ${ }^{27}$ as: disease in zone I, any stage with plus disease; disease in zone I, stage 3 without plus disease; or disease in zone II, stages 2 or 3 , with plus disease). ${ }^{28}$

As a matter of fact, the ideal criteria for the prevention of blindness caused by ROP depends on the particular characteristics of each country or even of regions within the same country. In India, in Latin American countries and in

Table 4 - Comparison of 18 patients with threshold disease according to U.S. and British screening criteria for retinopathy of prematurity

\begin{tabular}{|c|c|c|c|c|c|c|}
\hline Case & BW & GA & $\begin{array}{c}\text { Detected } \\
\text { USA 1997 } \\
\leq 1,500, \leq 28\end{array}$ & $\begin{array}{c}\text { Detected } \\
\text { USA } 2001 \\
\leq 1,250, \leq 28\end{array}$ & $\begin{array}{c}\text { Detected } \\
\text { UK 1996 } \\
\leq 1,500, \leq 31\end{array}$ & $\begin{array}{c}\text { Detected } \\
\text { UK 2005 } \\
\leq 1,250, \leq 30\end{array}$ \\
\hline 1 & 620 & 25 & Yes & Yes & Yes & Yes \\
\hline 2 & 625 & 26 & Yes & Yes & Yes & Yes \\
\hline 3 & 635 & 27 & Yes & Yes & Yes & Yes \\
\hline 4 & 700 & 26 & Yes & Yes & Yes & Yes \\
\hline 5 & 710 & 26 & Yes & Yes & Yes & Yes \\
\hline 6 & 755 & 25 & Yes & Yes & Yes & Yes \\
\hline 7 & 780 & 31 & Yes & Yes & Yes & Yes \\
\hline 8 & 870 & 30 & Yes & Yes & Yes & Yes \\
\hline 9 & 900 & 31 & Yes & Yes & Yes & Yes \\
\hline 10 & 920 & 30 & Yes & Yes & Yes & Yes \\
\hline 11 & 935 & 30 & Yes & Yes & Yes & Yes \\
\hline 12 & 990 & 29 & Yes & Yes & Yes & Yes \\
\hline 13 & 1.080 & 26 & Yes & Yes & Yes & Yes \\
\hline 14 & 1.230 & 31 & Yes & Yes & Yes & Yes \\
\hline 15 & 1.260 & 28 & Yes & Yes & Yes & Yes \\
\hline 16 & 1.315 & 32 & Yes & No & Yes & No \\
\hline 17 & 1.500 & 31 & Yes & No & Yes & No \\
\hline 18 & 710 & 29 & Yes & Yes & Yes & Yes \\
\hline
\end{tabular}

$\mathrm{BW}=$ birth weight; $\mathrm{GA}=$ gestational age. 
Eastern Europe, there is a tendency towards screening infants with $\mathrm{BW}>1,750 \mathrm{~g}$ or $\mathrm{GA}>34$ weeks, due to the fact that ROP was detected in several preterm infants with greater BW and higher GA. ${ }^{3,29}$

In our sample, the only case of ROP 5 occurred due to the loss of follow-up after hospital discharge.

The incidence of ROP in our study is likely to be even higher than observed, as there are no available data on the patients who died after the initial examination and who, for being more severely ill, could have reached higher RO stages if they had survived.

An adverse factor is that the whole group of patients originated from the same hospital, where perinatal care standards are applied on a routine basis to all preterm infants at very high risk. Since this is not a population-based study with patients from different hospitals, some of the observations described herein should be restricted to centers for neonatal care with similar characteristics to ours.

The Brazilian criteria fore neonatal screening after the 1st WK were efficient in detecting the cases that progressed to threshold disease. Bilateral blindness was averted in 17 infants during the study period.

The Brazilian screening criteria for ROP should be revised in the future in order to reduce the number of unnecessary exams; however, at this time, changes in these criteria may compromise the detection of treatable cases.

The program for prevention of blindness caused by retinopathy described here, if used by other public or private hospitals in Brazil, could reduce the national rates for preventable infant blindness caused by prematurity.

\section{References}

1. Gilbert C. Worldwide causes of childhood blindness. In: Hartnett ME, Trese M, Capone A Jr., Keats BJB, Steidl SM, editors. Pediatric retina. Philadelphia, USA: Lippincott Williams \& Wilkins; 2005. p. 315-29.

2. Gilbert C. Retinopathy of prematurity: epidemiology. J Comm Eye Health. 1997;10:22-4.

3. Gilbert C, Fielder A, Gordillo L, Quinn G, Semiglia R, Visintin P, et al. Characteristics of infants with severe retinopathy of prematurity in countries with low, moderate, and high levels of development: implications for screening programs. Pediatrics. 2005; 115:e518-25.

4. Lermann VL, Fortes Filho JB, Procianoy RS. The prevalence of retinopathy of prematurity in very low birth weight newborn infants. J Pediatr (Rio J). 2006;82:27-32.

5. Multicenter trial of cryotherapy for retinopathy of prematurity. Preliminary results. Cryotherapy for Retinopathy of Prematurity Cooperative Group. Arch Ophthalmol. 1988;106:471-9.
6. Grupo Retinopatia da Prematuridade Brasil. Relatório do I Workshop Retinopatia da Prematuridade. Sociedade Brasileira de Pediatria. 2002. http://www.sbp.com.br/show_item2.cfm? id_categoria=22\&id_detalhe $=1824 \&$ tipo_detalhe=s. Access: $15 / 11 / 2006$.

7. Zin A. Retinopatia da prematuridade: epidemiologia. Rev Soc Bras Retina e Vítreo. 2003;6:5-6.

8. An international classification of retinopathy of prematurity. The Committee for the Classification of Retinopathy of Prematurity. Arch Ophthalmol. 1984;102:1130-4.

9. An international classification of retinopathy of prematurity. II. The classification of the retinal detachment. The Committee for the Classification of the Late Stages of Retinopathy of Prematurity. Arch Ophthalmol. 1987;105:906-12.

10. Temporini ER, Kara-José N. Visual loss: prevention strategies. Arq Bras Oftalmol. 2004;67:597-601.

11. Fortes Filho JB, Lermann V, Barros CK, Innocente C, Costa MC, Procianoy RS. Prevalência da retinopatia da prematuridade no Centro de Neonatologia do Hospital de Clínicas de Porto Alegre. Rev HCPA. 2006;26:12-7.

12. Graziano RM, Leone CR, Cunha SL, Pinheiro AC. Prevalência da retinopatia da prematuridade em recém-nascidos de muito baixo peso. J Pediatr (Rio J). 1997;73:377-82.

13. Weber $C$, Weninger $M$, Klebermass $K$, Reiter $G$, WiesingerEidenberger $\mathrm{G}$, Brandauer $\mathrm{M}$, et al. Mortality and morbidity in extremely preterm infants ( 22 to 26 weeks of gestation): Austria 1999-2001. Wien Klin Wochenschr. 2005;117:740-6.

14. Azad R, Chandra P. Ultrasonic evaluation of retinopathy of prematurity. J Pediatr Ophthalmol Strabismus. 2005;42:197.

15. Foster A, Gilbert C. Epidemiology of childhood blindness. Eye. $1992 ; 6: 173-6$.

16. Zin A. The increasing problem of retinopathy of prematurity. J Comm Eye Health. 2001;14:58-9.

17. Graziano RM, Leone CR. Problemas oftalmológicos mais freqüentes e desenvolvimento visual do pré-termo extremo. J Pediatr (Rio J). 2005;81:S95-100.

18. Hussain N, Clive J, Bhandari V. Current incidence of retinopathy of prematurity, 1989-1997. Pediatrics. 1999;104:e26.

19. Palmer EA, Flynn JT, Hardy RJ, Phelps DL, Phillips CL, Schaffer $D B$, et al. Incidence and early course of retinopathy of prematurity. The Cryotherapy for Retinopathy of Prematurity Cooperative Group. Ophthalmology. 1991;98:1628-40.

20. Termote JU, Donders AR, Schalij-Delfos NE, Lenselink $\mathrm{CH}$, Derkzen van Angeren CS, Lissone SC, et al. Can screening for retinopathy of prematurity be reduced? Biol Neonate. 2005;88:92-7.

21. Screening examination of premature infants for retinopathy of prematurity. A joint statement of the American Academy of Pediatrics, the American Association for Pediatric Ophthalmology and Strabismus, and the American Academy of Ophthalmology. Pediatrics. 1997;100:273.

22. Retinopathy of prematurity: guidelines for screening and treatment. The report of a Joint Working Party of The Royal College of Ophthalmologists and the British Association of Perinatal Medicine. Early Hum Dev. 1996;46:239-58.

23. American Academy of Pediatrics. Section on Ophthalmology. Screening examination of premature infants for retinopathy of prematurity. Pediatrics. 2001;108:809-11. 
24. Ho SF, Mathew MR, Wykes W, Lavy T, Marshall T. Retinopathy of prematurity: an optimum screening strategy. J AAPOS. 2005;9:584-8.

25. Cryotherapy for Retinopathy of Prematurity Cooperative Group. Multicenter trial of cryotherapy for retinopathy of prematurity: ophthalmological outcomes at 10 years. Arch Ophthalmol. 2001;119:1110-8.

26. Early Treatment For Retinopathy Of Prematurity Cooperative Group. Revised indications for the treatment of retinopathy of prematurity: results of the early treatment for retinopathy of prematurity randomized trial. Arch Ophthalmol. 2003;121:1684-94.

27. International Committee for the Classification of Retinopathy of Prematurity. The International Classification of Retinopathy of Prematurity Revisited. Arch Ophthalmol. 2005;123:991-9.
28. Section on Ophthalmology American Academy of Pediatrics; American Academy of Ophthalmology; American Association for Pediatric Ophthalmology and Strabismus. Screening examination of premature infants for retinopathy of prematurity. Pediatrics. 2006;117:572-6.

29. Jalali S, Matalia J, Hussain A, Anand R. Modification of screening criteria for retinopathy of prematurity in India and other middle-income countries. Am J Ophthalmol. 2006;141:966-8.

Correspondence:

João Borges Fortes Filho

Rua Jaraguá, 672/202

CEP 90450-140 - Porto Alegre, RS

Tel.: +55 (51) 3333.4796, (51) 9969.8081

Fax: +55 (51) 3222.9292

E-mail: jbfortes@cursohbo.com.br 